\title{
Examining the Effects of Moral Development Level, Self-Concept, and Self-Monitoring on Consumers' Ethical Attitudes
}

\author{
Bahtışen Kavak \\ Eda Gürel \\ Canan Eryiğit \\ Öznur Özkan Tektaş
}

ABSTRACT. This study investigates the possible effects of self-concept, self-monitoring, and moral development level on dimensions of consumers' ethical attitudes. "Actively benefiting from illegal activities," "actively benefiting from deceptive practices," and "no harm/no foul 1-2" are defined by factor analysis as four dimensions of Turkish consumers' ethical attitudes. Logistic regression analysis is applied to data collected from 516 Turkish households. Results indicate that self-monitoring and moral development level predicted consumer ethics in relation to "actively benefiting from questionable practices" and "no harm/no foul" dimensions. Actual selfconcept is also a predictor variable in relation to "no harm/ no foul" dimension. Age and gender make significant differences in consumers' ethical attribute dimensions.

KEY WORDS: consumer ethics, moral development level, self-monitoring, self-concept, Turkey

\section{Introduction and purpose of the study}

In the area of marketing ethics, there are studies involving consumers, however most of them investigate consumers' ethical perceptions regarding business and marketing practices, rather than their perceptions of consumer practices (Vitell et al., 1991). Vitell et al. (1991) emphasize that "there is a 'gap' in the marketing ethics literature concerning the ethical beliefs and attitudes of the final consumers regarding potentially unethical consumer practices." Recently, Rao and Al-Wugayan (2005) pointed out that there is growing interest in researching consumer ethics.

Vitell (2003) states that there are mainly three major comprehensive theoretical models to explain the ethical decision-making process of individuals. They are the models of Ferrell and Gresham (1985), Hunt and Vitell (1986, 1993), and Trevino (1986). However, only the Hunt-Vitell model can easily be applied to consumers' ethical behavior. The model identifies the individual's moral philosophy or ethical ideology as the key factor in explaining the differences between the ethical judgments and behaviors of individuals. According to Hunt and Vitell (2006), this ethical evaluation process is influenced by several background factors including the cultural environment, professional, industry, and organizational environment, and personal characteristics of the individual. As seen, the Hunt-Vitell model contains several distinct background factors; however, only personal characteristics and cultural environment are relevant to consumer ethics (Vitell, 2003). Similar to the Hunt-Vitell model, other models also recognize the presence of both individual and situational variables in ethical decisionmaking. For instance, Ferrell and Gresham (1985) propose a contingency framework that proposes multifaceted factors in the process of ethical decision-making. According to their model, individual factors including knowledge, values, attitude, and intentions, interact with organizational factors including significant others and opportunity factors and influence the individual decision-maker facing an ethical dilemma. Trevino (1986) also identifies individual and situational factors as moderating variables in ethical decision-making.

Among the personal factors in the Hunt-Vitell model, a number of possible dimensions are proposed, including the individual's moral development level as suggested by Kohlberg (1981) and the 
individual's personality. Vitell (2003) states that the impact of several personal characteristics on the ethical judgments and intentions of individuals have been tested as independent variables. Among those, value consciousness, materialism, Machiavellianism, high propensity to take risk, high need for closure, age, and gender can be mentioned. Based on those findings, since various demographic/psychographic constructs were found to have influence on ethical judgment, Vitell (2003) suggests that "these as well as other personality variables should be included in subsequent research studies."

What is the relationship between the personality characteristics of a consumer and his ethical judgements? In the present study, moral development level, self-concept, and self-monitoring will be investigated as personality characteristics influencing the ethical attitudes of consumers. Although a few studies examined the relationship between moral development level and consumer ethics (e.g., Chen et al., 2008; Kavak et al., 2003; McGregor, 2006; Tan, 2002), in previous research self-concept and selfmonitoring in consumer ethics have been ignored. Therefore, the expected contribution of this study is to close this gap in the literature. In this framework, the present study will give special emphasis to examine the main and interaction effects of those selected personality factors on consumers' ethical attitudes. Theoretical foundations and the hypotheses of the study are presented in the following section.

\section{Theoretical foundations and hypotheses}

\section{Consumer ethics}

Ethics is defined as the "inquiry into the nature and grounds of morality where the term morality is taken to mean moral judgments, standards, and rules of conduct" (Taylor, 1975, p. 1). While Dodge et al. (1996) define consumer ethics as the "rightness as opposed to the wrongness of certain actions on the part of the buyer or potential buyer in consumer situations," Muncy and Vitell (1992, p. 298) define it as "the moral principles and standards that guide behavior of individuals as they obtain, use, and dispose of goods and services." A number of researchers (e.g., Swaidan et al., 2004, p. 752; Vitell, 2003, p. 33) point out that, although there is a large body of empirical research concerning ethics in the market place, most of them have focused on the seller side. As Rao and Al-Wugahan (2005) emphasize, marketing is an exchange process between buyers and sellers, and unethical behaviors can be exhibited by both parties. Therefore, ignoring consumers may result in an incomplete understanding of that process (Vitell, 2003) and in the development of ineffective marketing strategies (Swaidan et al., 2004). As a result, in the last decade, consumer ethics has emerged as an important area for research (Steenhaut and Kenhove, 2006).

Vitell (2003) reviews the major research studies involving consumer behavior that have appeared since 1990. Among the first consumer ethics research in this period, the studies of Muncy and Vitell (1992) and Vitell and Muncy (1992) should be mentioned. By developing a consumer ethics scale, these authors examined the extent to which consumers believe that certain questionable behaviors are ethical or unethical and found that consumers' ethical beliefs that differentiate their behaviors has four dimensions: (1) actively benefiting from illegal activities (e.g., changing price labels in a supermarket), (2) passively benefiting (e.g., getting too much change and not saying anything), (3) actively benefiting from deceptive (questionable) practices (e.g., using an expired coupon for merchandise), and (4) no harm/no foul (e.g., copying and using computer software that the consumer did not buy) (Vitell and Muncy, 1992). Their findings revealed that actions in the first dimension are initiated by consumers, most of whom perceive that these actions are illegal. The second dimension involves actions where consumers passively benefit from sellers' mistake. The third dimension is also initiated by the consumers, however these actions are not perceived to be illegal. Yet, they are still morally questionable. Study findings indicated consumers believe that it is more unethical to actively benefit from an illegal activity than to passively benefit. Finally, the fourth dimension involves actions that most consumers perceive as not even being unethical at all. Most of these actions involve the copying of intellectual property such as software, tapes or movies (Swaidan et al., 2004; Vitell, 2003).

Many individual factors influence consumers' ethical behaviors. Among those individual factors, demographic factors have received considerable 
research attention. Studies that investigated the relationships of age, gender, nationality, religion, and education with ethical decision-making have produced conflicting results (Loe et al., 2000; Lund, 2000; Rawwas and Singhapakdi, 1998; Vitell, 2003; Vitell et al., 1991; Ford and Richardson, 1994). However, age appears to be the most significant demographic variable, with older consumers being more ethical (Vitell, 2003). Regarding gender, although research results are mixed, some studies support that females are more ethical than males. For instance, in the context of Turkey, Ekin and Tezolmez (1999) report that, regarding their ethical judgments, Turkish business managers are significantly different only with respect to gender. Results indicated that female managers have higher ethics score than male managers. Ergeneli and Arıkan (2002) also supported this result for Turkish nonmanager salespeople, i.e., that females are more ethically sensitive than their male counterparts. In another study, using an Austrian sample, Rawwas (1996) found that gender is a significant determinant of not only the "actively benefiting from a questionable act" dimension but also the "no harm/no foul" dimension. However, as Vitell (2003) pointed out, the research findings regarding gender are certainly not definitive. As far as the other demographic factors such as educational level and income are concerned, more research is required, since results using these variables are also mixed.

Besides demographic variables, a number of researchers have studied the role of personal values on ethical decision-making, since it has been shown that personal values do affect a wide variety of attitudes and behaviors (Kagitcibasi, 2004, p. 360; Shafer et al., 2007). Several personal characteristics were tested as factors influencing ethical decisionmaking. Among the most frequently studied factors, Machiavellianism (Erffmeyer et al., 1999; Rawwas et al., 1994, 1996; Van Kenhove et al., 2001) and moral philosophy (Al-Khatib et al., 2002; Erffmeyer et al., 1999; Rawwas et al., 1995; Singhapakdi et al., 1999; Swaidan et al., 2004) should be mentioned. Overall, Vitell (2003) points out that less Machiavellian, less relativistic, and more idealistic consumers were found to be more ethical. Numerous other variables have also been examined; for instance, Rallapalli et al. (1994) examined the relationship between the consumer ethics scale and a number of personality traits, including high propensity to take risks, high needs for autonomy, innovation, and aggression. Findings showed that consumers with a high need to follow socially desirable behavior tended to be more ethical, as those with strong problem-solving coping styles. In a 5-year study, Glover et al. (1997), on the other hand, conducted three separate research studies. In the first two studies, they investigated the relationship between honesty/ integrity and ethical decision choices an individual makes and the moderating affects of self-monitoring and self-consciousness. Findings indicated that the degree of the influence of a particular value on ethical decision choice rests on demographical or environmental factors. Therefore, they expanded the third study by investigating the influence of the demographical factors that had provided the strongest results, including age, gender, and years of work experience, and some selected workplace values including achievement, fairness, and concern for others, on the ethical decision process. Findings indicated that gender, years of work experience, and achievement influence the ethical choices of individuals. In the study, women were found to be making more ethical decisions than men. In addition, years of work experience and high levels of need for achievement seemed to have correlation with higher levels of ethical decision-making.

In addition to personal characteristics, cultural environment has also attracted research attention. Rao and Al-Wugayan (2005) state that cross-cultural studies have started to appear in consumer ethics; however, considering the diversity of world cultures, their number is insufficient. In addition, most of them focus on a specific geographic region (Al-Khatib et al., 2002; Polonsky et al., 2001) or even in a single country (Al-Khatib et al., 1995; Chan et al., 1998; Erffmeyer et al., 1999; Van Kenhove et al., 2001). However, cross-cultural studies comparing different cultures (Al-Khatib et al., 1997; Rawwas, 2001; Rawwas et al., 1995) are also present. Overall, as stated by Vitell (2003), the findings of these studies support the relatively consistent factor structure of the Muncy-Vitell scale for consumer ethics. Consumer ethical judgments seem to be determined by three, instead of four, focal issues: (1) whether or not the consumer actively sought an advantage or was basically passive, (2) whether or not the activity might be perceived as illegal, and (3) 
whether or not there is any perceived harm to the seller (Vitell, 2003). In addition, "the 'actively benefiting from an illegal activity' items from the Muncy-Vitell scale are almost universally seen as being both illegal and unethical"' (Vitell, 2003, p. 40). Vitell (2003) suggests conducting additional studies using consumers from other cultures which are not tested yet.

\section{Self-concept}

Bracken (1992, p. 10) defines self-concept as "a multidimensional and context-dependent learned behavioral pattern that reflects an individual's evaluation of past behaviors and experiences, influences an individual's current behaviors, and predicts an individual's future behaviors" (quoted in Waugh, 2001, p. 87). On the other hand, according to Marsh (1990), self-concept is a person's perceptions regarding himself or herself (quoted in Waugh, 2001, p. 86). Zinkhan and Hong (1991, p. 348) note that "it is not an objective entity independent of the perceiver. Instead the term denotes individuals' subjective thoughts toward themselves. In this sense, it is a unique sort of attitude. Unlike other attitudes which are perceptual products of an external object, self-concept is an image shaped by the very person holding the image."

Although generally self-concept has been conceptualized with a multidimensional perspective, there is no consensus on the conceptualization of selfconcept in the consumer behavior literature. While some researchers discuss self-concept as a single variable, others conceptualize it having more than one component. Within the single self-construct tradition, self-concept has been labeled as "actual self," "real self," and "basic self," among others, and has been described as the perception of oneself. Within the multiple self-concept tradition, on the other hand, self-concept has often been treated as having two components: the actual self-concept and the ideal selfconcept. The ideal self-concept has been labeled as "ideal self," "idealized self," and "desired self," and has been defined as "the image of oneself as one would like to be" (Sirgy, 1982, p. 288).

Yet there are other researchers who have conceptualized self-concept under more than two dimensions. For instance, according to Shavelson et al. (1976), general self-concept is composed of four first-order facets labeled as academic selfconcept, social self-concept, emotional self-concept, and physical self-concept. Similarly, based on a multifaceted, hierarchical approach, Waugh (2001) conceptualized general self-concept, consisting of three first-order facets: academic self-concept, social self-concept, and presentation of self. Each was composed of three second-order facets. While academic self-concept has capability, perception of achievement, and confidence in academic life as the three second-order facets, social self-concept has same-sex peer, opposite-sex peer, and family. Presentation of self, on the other hand, has physical, personal confidence, and honesty/trustworthy subdimensions. As stated by the author, presentation of self is expected to be the easiest to achieve. In contrast, the other two are the hardest to achieve most of the time.

Although there are a number of approaches, most of the studies utilize ideal versus actual self-concept (Waugh, 2001). As Zinkhan and Hong (1991) point out, ideal self-concept is the ideal state of the imaginative self and therefore it is different from actual self-concept. While actual self-concept reflects the perceptual reality of oneself, ideal self-concept is shaped by imagination of the ideal self state. Zinkhan and Hong (1991, p. 348) also point out that "ideal self is the reference point with which actual self is compared," and when there is a gap between them, the individual tries to achieve the ideal self. In this sense, the ideal self is the driving force that motivates the individual upward. On the other hand, Grubb and Grathwohl (1967, p. 26) emphasize that "for the average person, self-concept and self-ideal overlap to a large extent, although in specific circumstances one or the other could be the chief motivator of behavior."

Heath and Scott (1998) point out that, in the consumer behavior literature, researchers have investigated the role of self-concept in a number of areas such as product perception, advertising perception, and advertising effectiveness; however much of the focus was on brand/product preference or purchase intention.

Grubb and Grathwohl (1967) review the literature in behavioral sciences and develop a theory of consumer behavior founded on self-theory and symbolism which can serve as a theoretical foundation to understand and predict consumer behavior. As they point out, an individual's self-concept, in other 
words, an individual's evaluation of him/herself, influences his behavior. According to the authors, individuals shape their behaviors to maintain and enhance their self-concept. As a result, consumers use goods as symbols and prefer products or product images that reflect their self-concept. The authors also emphasize that an individual's self is also shaped by others' reactions. In other words, an individual tries to develop or change his/her behavior to obtain positive reaction from his/her significant references such as his/her parents, peers or teachers. Therefore, individuals act in a manner not only to achieve their ideal self-concept, but also to receive positive reactions from their significant others.

Baack et al. (2000) use Social Penetration Theory to explain how various ethical issues might affect individuals. As noted by the authors, self-concept is an important part of an individual's core personality. The authors also note that, while some ethical dilemmas would have only minor concerns, others could penetrate the individual's central core. Accordingly, stronger reactions to ethical issues are exhibited in the attitudinal responses of the individual.

De Pelsmacker et al. (2005, p. 366) also point out that personal values seem to have a strong impact on an individual's ethical consumption behavior and add that "values are abstract principles that reflect an individual's self-concept." In addition, Rawwas et al. (2006, p. 72) state that "individuals with a positive self-concept tend to develop an ethical sense and recognize the role of conscience in life." On the other hand, negative personal attitudes are related with misconduct. Based on the literature above, therefore, we propose the following hypothesis;

H1: Consumers who have higher self-concept level will have higher ethical attitudes than consumers who have lower self-concept level.

\section{Moral development level}

Monga (2007, p. 179) states that "in order to act ethically an individual is expected to have a welldeveloped moral imagination and moral reasoning," and adds that literature on ethical reasoning supports that there is a positive relationship between moral reasoning and ethical behavior. Moral reasoning can be defined as "the cognitive processes people use in making ethical decisions" (Monga, 2007, p. 179, quoted from Trevino and Youngblood, 1990). In this respect, Kohlberg's model of cognitive moral development (CMD) has been the most widely recognized theory of moral reasoning (Elm and Nichols, 1993) focusing mainly on how decisions are made regarding what course of action is morally correct (Monga, 2007).

According to Kohlberg, there are three broad levels of CMD which progress from childhood until adolescence. These levels are labeled as preconventional, conventional, and postconventional (Goolsby and Hunt, 1992; Weeks et al., 2006). Each level contains two sequential stages and, in each of those stages, moral reasoning becomes more complex (Elm and Nichols, 1993; Powers and Hopkins, 2006).

At the preconventional level (stages 1 and 2), moral reasoning is founded on the maximization of self-gain and minimization of personal loss (Monga, 2007) and is based on punishments and rewards (Powers and Hopkins, 2006). At the conventional level (stages 3 and 4), what is morally right or wrong depends on the expectations of others (Monga, 2007). Thus, moral reasoning is based on norms and regulations of the society (Bommer et al., 1987). At the postconventional level (stages 6 and 7), which represents the highest level of moral development, people follow their self-chosen ethical principles and consider the welfare of everyone (Dubinsky et al., 2005; McGregor, 2006). At this level, in order to resolve moral dilemmas, individuals use universal concepts of rights and justice (Elm and Nichols, 1993). According to Kohlberg, while young children up to ages of 12 years are in stages 1 and 2, most adults are in conventional stages 3 and 4 (Ishida, 2006; Rawwas et al., 1998) and yet "only $20-25 \%$ of the adult population ever reaches the last two post-conventional stages" (Ishida, 2006, p. 65).

Kohlberg's three levels of CMD describe the relationships between the self and society's rules and expectations. While self-interest is the major concern at the preconventional level (Chang and Yen, 2007), the self is identified based on the expectations of others at the conventional level. Nevertheless, at the postconventional level, "person differentiates the self from the rules and expectations of others" (Arnold and Ponemon, 1991, p. 4). 
CMD is found to be significantly related to individual's ethical behavior (Ashkanasy et al., 2006; Chang and Yen, 2007; Izzo, 2000; Loe et al., 2000; O'Fallon and Butterfield, 2005). O'Fallon and Butterfield (2005) reviewed the empirical research findings in business ethics literature and concluded that, although there have been a few exceptions, literature generally provides empirical evidence for a positive relationship between CMD or ethical judgment and ethical decision-making. Thus, as stated by Monga (2007), findings suggest that individuals with higher level of moral reasoning scores are more likely to act ethically than individuals with lower moral reasoning scores.

Although most of the studies examining moral development have focused on managers and business students (e.g., Cherry and Fraedrich, 2000; Elm and Nichols, 1993; Monga, 2007; Robbin, 1989; Sheppard and Young, 2007; Uddin and Gillett, 2002), there have been a few studies concentrated on consumers' ethical behavior (e.g., Chen et al., 2008; Kavak et al., 2003; McGregor, 2006; Tan, 2002). However, empirical findings on the relationship between moral development and consumers' ethical behavior are not consistent; for instance, Tan (2002) investigated the influence of consumers' moral intensity, perceived risks, and moral judgment on their purchase intention of pirated software. Results revealed that consumers' purchase intention is influenced by CMD. On the other hand, Kavak et al. (2003) found that CMD level has no statistically significant influence on ethical evaluations of final consumers. Similarly, Chen et al. (2008) found that consumers' intention to illegally downloading music files, which has been regarded as a problem of consumer ethics by researchers, is not significantly related with moral reasoning ability. However, authors emphasize that this finding may be observed due to special characteristics of the product chosen for the study. Music resources are seen as public goods so that unauthorized downloading music may be perceived as not so unethical. Based on the above discussions, the following hypothesis is generated:

H2: Consumers who are at higher level of moral development will have higher ethical attitudes than those consumers who are at lower levels.

\section{Self-monitoring}

Self-monitoring is about self-observation and selfcontrol to notice situational cues for socially appropriate behavior in order to modify one's behavior accordingly (Snyder, 1974). In other words, "selfmonitoring refers to the extent to which an individual looks internally or externally for cues to appropriate behaviors in a given situation" (Snyder, 1974). According to Snyder (1974), individuals exercise control over their expressions in line with various norms of social appropriateness. However, there are important differences between individuals' degree of ability and willingness in monitoring their self-presentation, expressive behavior, and affective displays. In this respect, individuals can be grouped into two as 'high self-monitors' and 'low self-monitors.' High self-monitors are those individuals who are sensitive to the expression and self-presentation of others in social situations. Such individuals modify their expressive behavior from situation to situation for the sake of social approval in line with the social cues they gathered from the environment. In contrast, low selfmonitors are those individuals who have not acquired similar concern for social appropriateness. Such individuals do not engage in expressive control since their expressive behavior reflects their own inner attitudes, emotions, and dispositions (Gangestad and Snyder, 2000; Snyder, 1974). Underlying the selfmonitoring construct, there are five conceptual dimensions: concern with the social appropriateness of self-presentation, attention to social comparison information, control of self-presentation, and expressive behavior, strategic displays of self-presentation and affect states, and situational specificity of selfpresentation and expressive behavior (Leone, 2006).

Gangestad and Snyder (2000) review the published literature on self-monitoring and point out that the construct has been used in various research domains including consumer behavior. As Browne and Kaldenberg (1997, p. 31) quote from Guilford (1959) that "personality" can be defined as "a set of characteristics or traits that are relatively enduring and differentiate one person from another" and state that, among the various personality traits associated with marketplace behavior, self-monitoring has been investigated in a number 
of studies. An earlier research conducted by Becherer and Richard (1978) indicated that selfmonitoring acts as a moderating variable and, therefore, increases the ability of personality traits in predicting brand choice. However, the strongest moderating effect was observed among the low self-monitors. The findings indicated that the personality traits of low self-monitoring consumers predicted brand choice better that the personality traits of high self-monitoring consumers. In another study conducted by Snyder and DeBono (1987), it was found that high and low self-monitoring consumers respond differently to advertising depending on the variations in their concern for appearance. Based on the existing literature, DeBono (2006) particularly presents the study findings in two important areas of consumer behavior: advertising reactions and product evaluation. According to the research findings, high self-monitors seem to be responsive to image-oriented advertising, whereas low self-monitors seem to be responsive to quality-based advertising. Therefore, high self-monitors evaluate products on the basis of their potential to enhance their social image and status. Low self-monitors, on the other hand, evaluate products on the basis of their potential to perform their intended function. In addition, while high self-monitoring consumers focus on the exterior function of products, low self-monitoring consumers focus on the interior function of products.

Since its introduction, self-monitoring construct has attracted attention from social psychologists and personologists. In literature, there is substantial body of knowledge on the moderating role of selfmonitoring with respect to consumer behavior (Gangestad and Snyder, 2000). According to Gangestad and Snyder (2000, p. 532), "self-monitoring theory promised an appealing moderating variable resolution to debates concerning the relative roles of the person and the situation in determining behavior." In the domain of expressive behavior, rather than regarding behavior as a result of either traits or situations for all people for all times, self-monitoring construct suggests that behaviors of low self-monitors can be predicted from measures of their traits, whereas behaviors of high self-monitors can be predicted from features of their situations. Accordingly, Gangestad and Snyder (2000, p. 532) state that "attitudes should be good predictors of behavior for low self-monitors but poor predictors for high self-monitors."

Research from other related domains may include consumer ethics. However, our search revealed that in literature there is no empirical research that investigated the relationship between consumer ethics and self-monitoring. The two important research studies that investigated the relationship between ethical decision-making and self-monitoring were conducted by Uddin and Gillett (2002) and Ross and Robertson (2003). In their study, Ross and Robertson (2003) found that personal factors act independently and interact with situational factors in ethical decision-making. Besides demographic factors, personality factors such as Machiavellianism and self-monitoring presented to have main effects on ethical decision-making. Contrary to the authors' propositions, high self-monitors were not more likely to respond to the ethical clarity of the firm. Since high self-monitors take their behavioral cues from their social environment, they were expected to be more influenced by universal factors in the institutional environment such as ethical clarity and incentive compensation. On the other hand, Uddin and Gillett (2002) found that, contrary to their expectations, low self-monitors were found to be more influenced by the attitudes of others (subjective norms) than high self-monitors when forming intentions to act in an unethical manner. As seen, research findings regarding the influence of selfmonitoring produced conflicting results. Quoting from Covey et al. (1988), Uddin and Gillett (2002) state that, as high self-monitors adjust their selfpresentations based on their perception of the demands of the situation, they cheat in their selfpresentation; therefore, they are more likely to intend to cheat in a task. Therefore, we hypothesize:

H3: High self-monitoring consumers will behave more ethically than low self-monitoring consumers.

There are a few studies (Elm and Nichols, 1993; Gutkin and Suls, 1979) in the literature investigating the relationship between moral reasoning and selfmonitoring. For instance, Elm and Nichols (1993) examined the influence of ethical climate and 


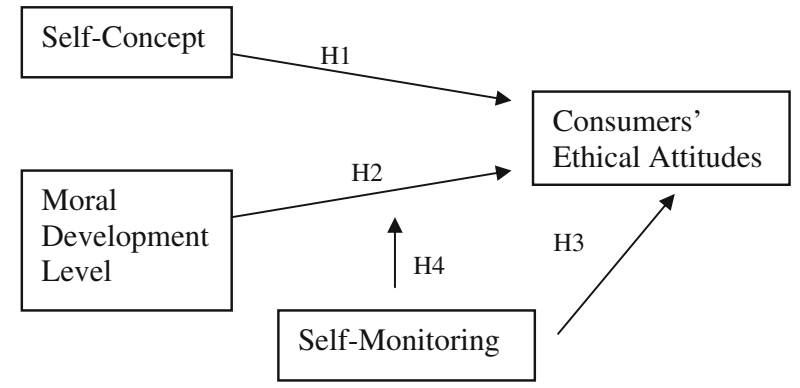

Figure 1. Model of consumer ethical attitudes.

self-monitoring on moral reasoning of managers. According to results of the study, a manager's moral reasoning level is not affected by the ethical climate of the organization, his/her self-monitoring or the interaction of these two factors. On the other hand, there have been contrary findings in the past literature. Gutkin and Suls (1979) investigated the relationships between ethical attitudes, CMD level, internalexternal locus of control, and self-monitoring for college students. The study revealed that students who are at conventional level of CMD have high self-monitoring scores. This finding is consistent with theoretical knowledge indicating that at this level people conform to social norms and rules for welfare (Elm and Nichols, 1993). Therefore, we hypothesize;

H4: Self-monitoring moderates the effect of moral development on consumers' ethical attitudes.

Based on the above hypotheses, the model shown in Figure 1 is proposed.

\section{Methodology}

\section{Questionnaire development and measurement}

The required data for this research was gathered through a self-administered questionnaire. The research questionnaire was divided into five parts. The first part consisted of CMD level questions. The second part contained self-monitoring questions. Consumer ethics questions were included in the third part. The fourth part consisted of self-concept questions, and finally the last part contained demographic questions to capture the profile of the participants.
The CMD level of respondents was measured using the Defining Issues Test (DIT) developed by Rest (1979), who incorporated Kohlberg's six stages of CMD in the instrument. Compared with Kohlberg's original measurement, the Moral Judgment Interviews (MJI), which require in-depth interviews and scoring by trained judges, DIT is relatively easy to administer due to its multiplechoice questionnaire format. As a result, it has been the most widely used instrument to measure CMD. In addition, the Cronbach's alpha internal consistency of this instrument has been reported to be high, around 0.70s and 0.80s (Ishida, 2006, pp. 63, $65,66)$. The DIT can be applied in either six- or three-story/ethical dilemma format. In this study, the short form consisting of three stories was utilized. The ethical dilemmas of "Heinz and the drug," "escaped prisoner," and "the doctor's dilemma" were incorporated into the questionnaire. Each dilemma was followed by a set of 12 statements representing a particular stage of CMD. As suggested by Rest (1979), participants were asked to rate each statement for its importance by using a five-point Likert scale ranging from "great importance" to "no importance" in making their judgment, and then they are asked to select the four most important statements and rank-order them from one to four (Ishida, 2006, p. 65; Rest, 1979). Besides calculating the P-score of each respondent as suggested by Rest (1979), we determined their moral development stage by looking at the highest score of each respondent and its correspondence with the appropriate moral development stage.

Self-monitoring is assessed by using a widely utilized measure: Snyder and Gangestad's (1986) 18-item Self-Monitoring Scale. Snyder (1974, p. 529) says "self-monitoring would probably best be measured by an instrument specifically designed to discriminate individual differences in concern for social appropriateness, sensitivity to the expression and self-presentation of others in social situations as cues to social appropriateness of self-expression, and use of these cues as guidelines for monitoring and managing self-presentation and expressive behavior." Accordingly, he developed the SelfMonitoring Scale. The original scale consisted of 25 true/false questions. As Snyder (1974) reported, the scale was internally consistent, stable, and 
uncorrelated with measures of related concepts. However, the scale had been criticized based on factor analysis results in various studies that indicated multifactorial structure and raised questions about the very existence of self-monitoring (Gangestad and Snyder, 2000). Based on the arguments, Snyder and Gangestad (1986) purified the original scale and proposed a shortened 18-item Self-Monitoring Scale which had an approximately 0.70 reported internal consistency. Leone (2006) points out that, in studies, while some researchers use the 25-item Self-Monitoring Scale (e.g., Uddin and Gillett, 2002), others utilize the 18-item Self-Monitoring Scale (e.g., Browne and Kaldenberg, 1997), and still others use subsets of items from those two scales (e.g., Bodey and Grace, 2006; Ross and Robertson, 2003). In this study, we utilized the 18-item true/false SelfMonitoring Scale which includes ten reverse statements. Typical statements found on the SelfMonitoring Scale include: (1) "I'm not always the person I appear to be," and (2) "I would probably make a good actor." As Browne and Kaldenberg (1997) emphasized, the scale was scored in the direction of high self-monitoring; therefore, higher scores indicated higher self-monitoring. "Participants received one point for each item they endorsed in the high self-monitoring direction. For eight items, a response of 'True' was the high selfmonitoring response; for the remaining 10 items, a response of 'False' was the high self-monitoring response" (Ratner and Kahn, 2002, p. 251).

Consumers' ethical attitude was measured by utilizing the consumer ethics scale (Muncy Vitell Questionnaire - MVQ) developed by Muncy and Vitell (1992) and administered and validated in Turkey by Kavak et al. (2003). In the study, 15 consumer situations having ethical implications were utilized from the consumer ethics scale used by Rawwas et al. (1998). Two items were eliminated from the instrument used by these authors, since they were found unsuitable to the Turkish culture. These items included the following: "paying a nominal charge for an international call" and "observing someone shoplifting and ignoring it." Respondents were asked to evaluate the 15 unethical situations by using a five-point Likert scale with higher scores indicating a more intolerant judgment, i.e., ethical disposition $(1=$ very appropriate, to $5=$ very inappropriate).
Self-concept is measured by using the multifaceted, hierarchical self-concept scale developed by Waugh (2001). The scale consists of four subscales: academic self-concept, social self-concept, presentation of self, and honest/trustworthy self-concept. Since the population of this study includes households, the academic self-concept subscale, which is more appropriate for student samples, was not included in the questionnaire. Therefore, the total number of items measuring self-concept in this study was 30. As in Waugh (2001), the questions were presented under two columns, one for "how I would like to be" and another for "how I actually am," and the response categories were labeled in an ordered format with $0=$ "none of the time" or "almost non of the time," 1 = "some of the time," $2=$ "most of the time," and $3=$ "all the time" or "nearly all the time."

Demographic questions included age, gender, educational level, and income level. Age and gender were particularly included as control variables based on the previous research findings outlined in the previous section.

All scales used in the instrument, and a typical example for DIT, is presented in the Appendix.

\section{Sampling and data collection}

Convenience sampling was conducted for the sampling process in the study. The sample of the study included households in Ankara. University students were employed to collect data from various areas in the city representing different socio-economic groups.

In the study, 670 questionnaires were administered. In order to check respondent reliability regarding DIT, the M-score of each participant was computed and those participants with a high M-score were discarded. A participant's M-score is calculated by using the "filler" statements which do not represent any stage of thinking but rather represent a participant's tendency to endorse statements for their pretentiousness rather than meaning; therefore participants with a high M-score should be discarded. This score is widely used to check reliability of DIT (e.g., Goolsby and Shelby, 1992; Ishida, 2006; Izzo, 2000; Sheppard and Young, 2007). Based on Rest's (1979) standards, 129 cases 
TABLE I

Sample descriptive

\begin{tabular}{lcc}
\hline & $N$ & $\%$ \\
\hline Average family income & (New & Turkish Liras - YTL) \\
$\quad$ Low & 24 & 4.7 \\
Medium & 368 & 71.3 \\
High & 124 & 24 \\
Age (years) & & \\
18-24 & 121 & 23.4 \\
$25-30$ & 169 & 32.8 \\
31-44 & 132 & 25.6 \\
45 and above & 94 & 18.2 \\
Educational level & & \\
Undergraduate & 126 & 24.4 \\
Graduate & 272 & 52.7 \\
Postgraduate & 118 & 22.9 \\
Gender & & \\
Female & 259 & 50.2 \\
Male & 257 & 49.8 \\
\hline
\end{tabular}

$N=516$

with high $M$-score $(\geq 4)$ were eliminated. According to the author, it seems to be typical to lose between $5 \%$ and $15 \%$ of a sample due to the reliability checks. In addition, 25 cases were removed due to missing demographic data. The final sample size was 516 . Table I provides summary statistics for the sample.

\section{Results}

Factor analysis

As mentioned, to measure consumers' ethical attitudes, we used the consumers ethical scale (MVQ) developed by Muncy and Vitell (1992). As pointed out by Vitell (2003), the factor structure of this scale generally supports a three-factor solution. Similar to other studies (e.g., Rawwas and Singhapakdi, 1998) our exploratory factor analysis results in Table II suggested a three-factor structure rather than four.

In our analysis, while a four-factor solution accounted for $59.3 \%$ of the variance, a three-factor solution accounted for $48.5 \%$. The Kaiser-MeyerOlkin measure of sampling adequacy was 0.87 . As a result, we rotated the solution using a Varimax rotation procedure. However, this procedure did not produce the same factor structure proposed by Muncy and Vitell (1992). In our analysis, we observed that, although the first dimension described behaviors that can be labeled as "actively benefiting from illegal activity" (factor 1) and included those items which are almost universally perceived as illegal and initiated by the consumer as suggested by the researchers, the second dimension can be labeled as "benefiting from questionable action" (factor 2), since based on the item loadings, this dimension included those items with questionable behaviors which are not necessarily illegal (e.g., not saying anything when the waitress miscalculates the bill in his/her favor). The third dimension, labeled as "no harm/no foul" (factor 3) included those items that may be considered permissible by the consumers, since most perceive them as having consequences with little or no harm. However, in the Turkish context, we observed that those items related to downloading or copying software, tapes or movies and the other items under the "no harm/no foul" dimension that most consumers perceive as even being unethical at all such as "returning a merchandise after trying it and not liking it" produced the fourth dimension (factor 4). In addition, in the Turkish context, we observed that "taking an ashtray or other souvenir from a hotel or a restaurant" item under the "no harm/no foul" dimension appeared under the "benefiting from questionable action" (factor 2) dimension. Based on our exploratory factor analysis and literature, the three factor solution made better conceptual sense. The results of the factor analysis can be seen in Table II.

In summary, based on our factor analysis, in the Turkish context, the first dimension of consumer ethics included items 1,2, and 3 and was labeled as "actively benefiting from illegal activity," similar to the original proposed by Muncy and Vitell (1992); the second dimension included items $4,5,6,7,8$, and 13 and was labeled as "benefiting from questionable action;" finally, the third dimension included items 9, 10,11, 14, and 15 and was labeled as "no harm/no foul." Except for the exclusion of item 13, this factor is also similar to the factor structure proposed by Muncy and Vitell (1992). 
TABLE II

Exploratory factor analysis of the MVQ instrument

\begin{tabular}{|c|c|c|c|c|c|}
\hline No. & Item & Factor 1 & Factor 2 & Factor 3 & Factor 4 \\
\hline 1 & Changing price-tags on merchandise in a store & .792 & & & \\
\hline 2 & $\begin{array}{l}\text { Giving misleading price information to a clerk } \\
\text { for unpriced item }\end{array}$ & .646 & 412 & & \\
\hline 3 & $\begin{array}{l}\text { Drinking a can of soda in a supermarket without } \\
\text { paying for it }\end{array}$ & .657 & & & \\
\hline 4 & Lying about a child's age to get a lower price & & 462 & & .517 \\
\hline 5 & Getting too much change and not saying anything & & .743 & & \\
\hline 6 & $\begin{array}{l}\text { Not saying anything when the waitress } \\
\text { miscalculates the bill in your favor }\end{array}$ & & .753 & & \\
\hline 7 & $\begin{array}{l}\text { Not telling the truth when negotiating the } \\
\text { price of new automobile }\end{array}$ & & .596 & & .442 \\
\hline 8 & $\begin{array}{l}\text { Breaking a bottle of salad dressing in a supermarket } \\
\text { and doing nothing about it }\end{array}$ & & .555 & & .402 \\
\hline 9 & Taping a movie off the television & & & & .829 \\
\hline 10 & Using computer software or games you did not buy & & & & .828 \\
\hline 11 & Tasting grapes in a supermarket and not buying any & & & .665 & \\
\hline 12 & Recording an album instead of buying it & & & & .757 \\
\hline 13 & $\begin{array}{l}\text { Taking an ashtray or other "souvenir" from a } \\
\text { hotel or restaurant }\end{array}$ & & .497 & & \\
\hline 14 & $\begin{array}{l}\text { Returning merchandise after trying it and } \\
\text { not liking it }\end{array}$ & & & .686 & \\
\hline 15 & $\begin{array}{l}\text { Spending over an hour trying on different } \\
\text { dresses and not purchasing any }\end{array}$ & & & .808 & \\
\hline
\end{tabular}

Factor 1: "actively benefiting from illegal activity." Factor 2: "benefiting from questionable action." Factor 3: "no harm/ no foul 1." Factor 4: "no harm/no foul 2."

\section{Test of reliability}

A reliability assessment of all measures of the study was carried out. The observed reliability coefficients (Cronbach's alpha) were 0.69 for self-monitoring, 0.93 for ideal self-concept, 0.92 for actual self-concept, 0.54 for "actively benefiting from illegal activity," 0.77 for "benefiting from questionable action," and 0.79 for "no harm/no foul" dimensions of consumer ethics. Thus, the scales have acceptable internal consistency. As stated by Wincent and Westerberg (2005), in this type of exploratory studies, according to Nunnally (1978), values down to 0.50 are acceptable.

\section{Multivariate analysis}

The dependent variables of this study included the three dimensions of consumer ethics. Therefore, we tested our hypotheses by producing different regression equations by using these three dependent variables. The independent variables included actual self-concept, ideal self-concept, moral development level, and self-monitoring. Age and gender were included in our analyses as control variables.

We used logistic regression analysis to test our hypotheses, since the distributions of the dependent variables were extremely skewed and no transformation seemed to help, as suggested by Tabachnick and Fidell (1996), we dichotomized the dependent variables by splitting them into two from their median. Respondents having higher ethical scores (those ones with scores over the median) were coded as " 1 " and others as "0." As Hair et al. (1998, p. 321) stated, logistic regression is an alternative to discriminate analysis and beneficial due to its similarity to multiple regressions. It is suited for models where the dependent variable is dichotomous (Hair 
TABLE III

Results of logistic regression analysis

\begin{tabular}{|c|c|c|c|c|c|c|}
\hline & B & SE & Wald & df & Significance & $\operatorname{Exp}(B)$ \\
\hline \multicolumn{7}{|l|}{ Model $1 \mathrm{CE}^{\mathrm{a}}$} \\
\hline Constant & 0.127 & 0.127 & 0.987 & 1 & 0.320 & 1.135 \\
\hline Age & 0.011 & 0.008 & 1.910 & 1 & 0.167 & 1.012 \\
\hline Gender & 0.174 & 0.183 & 0.910 & 1 & 0.340 & 1.190 \\
\hline Ideal self-concept & 0.000 & 0.009 & 0.001 & 1 & 0.974 & 1.000 \\
\hline Actual self-concept & 0.002 & 0.009 & 0.045 & 1 & 0.833 & 1.002 \\
\hline Self-monitoring (SM) & 0.050 & 0.029 & 3.017 & 1 & $0.082 \star \star$ & 1.052 \\
\hline Moral development level (MDL) & -0.022 & 0.120 & 0.032 & 1 & 0.857 & 0.979 \\
\hline Interaction $(\mathrm{SM} \times \mathrm{MDL})$ & -0.008 & 0.041 & 0.042 & 1 & 0.837 & 0.992 \\
\hline \multicolumn{7}{|l|}{ Model 2 CE2 $2^{\mathrm{a}}$} \\
\hline Constant & 0.060 & 0.135 & 0.194 & 1 & 0.659 & 1.061 \\
\hline Age & 0.034 & 0.009 & 13.702 & 1 & $0.000^{\star}$ & 1.034 \\
\hline Gender & 0.077 & 0.192 & 0.161 & 1 & 0.688 & 1.080 \\
\hline Ideal self-concept & 0.005 & 0.010 & 0.214 & 1 & 0.643 & 1.005 \\
\hline Actual self-concept & 0.008 & 0.010 & 0.625 & 1 & 0.429 & 1.008 \\
\hline Self-monitoring (SM) & 0.165 & 0.032 & 26.930 & 1 & $0.000^{\star}$ & 1.179 \\
\hline Moral development level (MDL) & 0.417 & 0.140 & 8.855 & 1 & $0.003^{\star}$ & 1.517 \\
\hline Interaction $(\mathrm{SM} \times \mathrm{MDL})$ & 0.058 & 0.047 & 1.485 & 1 & 0.223 & 1.060 \\
\hline \multicolumn{7}{|l|}{ Model 3 CE $3^{\mathrm{a}}$} \\
\hline Constant & -0.063 & 0.135 & 0.217 & 1 & 0.642 & 0.939 \\
\hline Age & 0.050 & 0.009 & 27.194 & 1 & $0.000^{\star}$ & 1.051 \\
\hline Gender & 0.337 & 0.193 & 3.041 & 1 & $0.081 \star \star$ & 1.400 \\
\hline Ideal self-concept & -0.001 & 0.010 & 0.007 & 1 & 0.934 & 0.999 \\
\hline Actual self-concept & 0.019 & 0.010 & 3.783 & 1 & $0.052^{\star \star}$ & 1.020 \\
\hline Self-monitoring (SM) & 0.126 & 0.031 & 16.169 & 1 & $0.000^{\star}$ & 1.134 \\
\hline Moral development level (MDL) & 0.234 & 0.136 & 2.951 & 1 & $0.086^{\star \star}$ & 1.263 \\
\hline Interaction $(\mathrm{SM} \times \mathrm{MDL})$ & -0.063 & 0.135 & 0.217 & 1 & 0.642 & 0.939 \\
\hline
\end{tabular}

Gender was coded dichotomously $(0=$ men, $1=$ women $)$.

${ }^{a}$ CE1 (factor 1) "actively benefiting from illegal activity," CE2: (factor 2) "benefiting from questionable action," CE3: (factor 3) "no harm/no foul".

$\star_{p}<0.01 ;{ }^{\star \star} p<0.10$.

et al., 1998, p. 314). Table III present the results of our analysis.

In the direct logistic regression model, where "actively benefiting from illegal activity" (CE1) was the dependent variable, the test of the full model with all predictors against a constant-only model was not statistically reliable $\left[\chi^{2}(7, N=516)=7.743\right.$; $p<0.356]$, indicating that the predictors, as a set, do not reliably distinguish between consumers having high and low "actively benefiting from illegal activity" (CE1) scores. Prediction success was unimpressive, with $26.8 \%$ of the consumers having low "actively benefiting from illegal activity" scores and $84.9 \%$ of the consumers having high "actively benefiting from illegal activity" scores correctly predicted, for an overall success rate of $58.9 \%$.

In the direct regression model, where "benefiting from questionable action" (CE2) was the dependent variable, the test of the full model with all predictors against a constant-only model was statistically reliable $\left[\chi^{2}(7, N=516)=65.234 ; p<0.000\right]$, indicating that the predictors, as a set, reliably distinguish between consumers having high and low "benefiting from questionable action" (CE2) scores. Prediction success was moderate, with $61.7 \%$ of the consumers having low "benefiting from questionable action" scores and $66.8 \%$ of the consumers having high "benefiting from questionable action" 
scores correctly predicted, for an overall success rate of $64.3 \%$.

In our third direct regression model, where "no harm/no foul" (CE3) was the dependent variable, the test of the full model with all predictors against a constant-only model was statistically reliable, $\left[\chi^{2}(7, N=516)=69.640 ; p<0.000\right]$, indicating that the predictors, as a set, reliably distinguish between consumers having high and low "no harm/no foul" (CE3) scores. Prediction success was moderate, with $64.9 \%$ of the consumers having low "no harm/ no foul" scores and $63.1 \%$ of the consumers having high "no harm/no foul" scores correctly predicted, for an overall success rate of $64.0 \%$.

Table III shows regression coefficients, standard errors, Wald statistics, odds ratios, and $90 \%$ confidence intervals for odds ratios for each of the predictors. According to the Wald criterion, in the first model, where "actively benefiting from illegal activity" (CE1) was the dependent variable, except for self-monitoring no variables reliably predicted consumer ethics in relation to "actively benefiting from illegal activity." In the second model, where "benefiting from questionable action" (CE2) was the dependent variable, age, self-monitoring, and moral development level reliably predicted consumer ethics in relation to this dimension. Finally, in the third model, where "no harm/no foul" (CE3) was the dependent variable, age, gender, self-monitoring, and actual self-concept reliably predicted consumer ethics in relation to this dimension.

Based on these results, $H 1$, which stated that consumers having higher self-concept level will have higher ethical attitudes than consumers having lower self-concept level, is partially accepted. According to the findings, although both actual self-concept and ideal self-concept had positive relationship with all the consumers' ethics dimensions, except for actual self-concept in relation to the "no harm/no foul" dimension, they did not produce statistically significant results.

With $H 2$, we proposed that consumers who are at higher level of moral development will have higher ethical attitudes than those consumers who are at lower levels. Regarding moral development level, our logistic regression analysis showed that it is a significant discriminator in the "actively benefiting from questionable practices" and "no harm/no foul" dimensions. This suggests that, as the moral development level of a consumer increases, his/her ethical attitudes concerning such practices increase. Thus, $H 2$ is partially supported.

$H 3$, which stated that high self-monitoring consumers will have higher ethical attitudes than low self-monitoring consumers, is supported. According to the findings, self-monitoring significantly affects consumers' ethical attitudes regarding all three dimensions of consumers' ethics. Thus, this finding suggests that high self-monitoring individuals have higher consumer ethical attitudes.

Finally, with $\mathrm{H} 4$ we proposed a moderating effect of self-monitoring on the relationship between moral development level and consumers' ethical attitudes. Contrary to our expectations, this hypothesis was not supported. This suggests that the effect of moral development level on consumers' ethical behavior does not change when the effect of self-monitoring is concerned.

Regarding demographic factors, age seems to affect consumers' ethical attitudes, when "benefiting from questionable action" and "no harm/no foul" practices are concerned. This result suggests that, in the Turkish context, older consumers are more ethical. Results also indicate the presence of some gender issues in consumers' ethical attitudes, especially regarding the "no harm/no foul" dimension. The positive relationships between all dimensions of costumers' ethical attitudes and gender suggest that women have higher ethical attitudes than men.

\section{Discussion and conclusion}

The purpose of this study is to investigate the relationship between personality characteristics including self-concept, self-monitoring, and moral development level, and consumers' ethical attitudes. Data from 516 households has been analyzed by using logistic regressions. Exploratory factor analysis has also been conducted to investigate the factor structure of Muncy-Vitell's consumer ethics scale (MVQ).

The authors of this study focus on a single country, Turkey. Considering the recent ethical climate in the country, where ethical violations involving politicians and business professionals are common practice, and the country is suffering from a number of ethical problems such as tax fraud, deceptive advertising, production of unsafe products (Rawwas et al., 2005), 
and copyright piracy (Duran, 2008), we believe that it may be interesting to examine ethical issues in the marketplace from the perspective of consumer ethics in such an environment. With the exception of Rawwas et al. (2005), Kavak et al. (2003), and Kavak's (2001) studies, available literature on ethics in Turkey concentrates on business ethics (Ekin and Tezolmez, 1999; Ergeneli and Arıkan, 2002; Menguc, 1998; Yaman and Gurel, 2006).

Based on our factor analysis, in the Turkish context, the findings suggest a three-dimensional factor structure for consumers' ethical attitudes which may be labeled as "actively benefiting from illegal activities," "actively benefiting from questionable practices," and "no harm/no foul." The observed factor structure for Turkish consumers' ethical attitudes is consistent with those observed in other studies conducted in a number of different countries (Vitell, 2003). However, an interesting finding of our factor analysis is that items related to copying and using software that the consumer did not buy under the "no harm/no foul" dimension produced another dimension with the lowest mean score among the others. Therefore, we may state that Turkish consumers are least ethical concerning software piracy, which, as reported by Duran (2008), makes up 64\% of Turkey's $\$ 1$ billion software industry. This finding may suggest that Turkish consumers perceive that these actions are not unethical at all. Husted (2000) investigated the impact of national culture on software piracy and found that GNP per capita, income inequality, and individualism have negative statistically significant relationships with software piracy. According to Hofstede's (1983) cultural typology, Turkey is a collectivist nation with a GNP below the world average and a large middle class. In this respect, we can state that our findings support the study findings of Husted (2000) and that software piracy may have some issues hidden in the culture.

In order to test the hypotheses of the study, logistic regression analyses were conducted. These analyses showed that the first model, with the "actively benefiting from illegal activities" dimension of MVQ as the dependent variable, was not significant. As suggested by Vitell (2003, p. 40) this dimension is perceived as being both illegal and unethical universally. As a result, especially the other two dimensions, "actively benefiting from questionable practices" and "no harm/no foul," could better discriminate consumers from different cultures. Thus, this suggestion of Vitell (2003) is supported for Turkish consumers as well.

With respect to the self-monitoring variable, results indicate that, as expected, high self-monitoring individuals have higher ethical attitudes regarding all dimensions of consumer ethics. Since high self-monitoring individuals take their behavioral cues from their social environment (Ross and Robertson, 2003), the results could confirm the study findings of Rawwas et al. (2005, p. 191), who concluded that "Turkish consumers tend to avoid uncertainties by following rules and norms." As Turkish individuals seem to follow universal rules and norms when questionable situations arise, the results are especially supportive regarding the "actively benefiting from questionable action" dimension of consumer ethics. O'Fallon and Butterfield (2005) review the business ethics literature and call for attention to the limited number of studies that have investigated the influence of moderating variables in ethical decision-making. As they suggest, examining such effects would help us broaden understanding on ethical decision-making. Therefore, we tested the influence of self-monitoring in the relationship between moral development level and consumers' ethics. However, as in the study of Glover et al. (1997), self-monitoring did not have a moderating influence. Yet, an important implication of this study is that, although self-monitoring does not have a moderating effect between the moral development level of consumers and their ethics, it is an important determinant of consumer ethics. High self-monitoring consumers seem to have higher ethics. Therefore, our findings support Rallapalli et al. (1994), who found that consumers with a high need to follow socially desirable behavior tend to be more ethical.

When the moral development level of consumers is concerned, it is also found that, as expected, moral development level has positive relationship with consumers' ethical attitudes. However, this relationship is only statistically significant with respect to the "actively benefiting from questionable practices" and "no harm/no foul" dimensions. As mentioned above, rather than the "actively benefiting from illegal activities" dimension, the other two dimensions of MVQ are better constructs to differentiate consumers in different cultures. The moral reasoning 
stage of most Turkish consumers (93\%) appears to be stages 3 and 4 . This reflects moral reasoning at the conventional level as proposed by Kohlberg. As pointed out by a number of researchers (e.g., Ishida, 2006), most adults are in this stage, where moral reasoning is based on the expectations of others and norms and regulations of the society. Previous research findings on business ethics in Turkey have already demonstrated that Turkish managers closely follow ethical principles and norms (Rawwas et al., 2005). Based on our findings, therefore, we can claim that, first, similar to managers, moral reasoning of most adults in Turkey are in line with society's ethical norms and regulations. Second, we may also claim that the moral reasoning level of our sample of households who participated in this study represent the moral reasoning level of most adults. Third, as most of these individuals seem to be at the conventional level of moral reasoning, and therefore behave based on the norms and regulations of the society, we can also claim that this finding is consistent with our findings with respect to self-monitoring.

Although the findings in relation to self-concept, as a personality characteristic in consumers' ethical attitudes, did not produce strong statistically significant results, the relationship between this variable and the three dimensions of consumer ethics seem to be positive, as expected.

In this study, results concerning gender indicated that women are more ethical than men, though this finding cannot be conclusive due to mostly nonsignificant results. However, as in the study of Rawwas (1996) with an Austrian sample, gender seems to make a difference when some, but not all, dimensions of consumers' ethics are concerned. Rawwas (1996) reports that gender is a significant determinant of the "actively benefiting from a questionable action" and "no harm/no foul" dimensions. Similarly in Turkey, gender seems to play some part especially when the "no harm/no foul" dimension is concerned. However, we believe that more research is required involving this variable in ethics studies, as gender seems to play a part only in some dimensions of consumers' ethics. This finding may explain the conflicting research results regarding gender in literature.

Regarding age, the findings are consistent with a number of research results. In the Turkish context, results indicate that older consumers have higher ethical attitudes.

An important limitation of this research is that, although we may claim that the sample population is representative of the average consumer in Turkey, this may not be the case. In order to be able to generalize the findings of this study, therefore, future research is warranted to investigate the issues in this study further.

As ethical decision-making in marketing is an important issue, future research should investigate the role of personality characteristics on consumer ethics by increasing the number of variables that are theorized to have influence on consumer ethical decision-making. Future research can also be conducted to study consumer ethics in different cultures.

\section{Appendix}

Defining Issues Test

Heinz and the drug

In Europe a woman was near death from a special kind of cancer. There was one drug that doctors thought might save her. It was a form of radium that a druggist in the same town had recently discovered. The drug was expensive to make, but the druggist was charging ten times what the drug cost to make. He paid $\$ 200$ for the radium and charged $\$ 2,000$ for a small dose of the drug. The sick woman's husband, Heinz, went to everyone he knew to borrow the money, but he could only get together about $\$ 1,000$, which is half of what it cost. He told the druggist that his wife was dying, and asked him to sell it cheaper or let him pay later. But the druggist said, "No, I discovered the drug and I'm going to make money on it." So Heinz got desperate and began to think about breaking into the man's store to steal the drug for his wife. Should Heinz steal the drug?

Please rate the following statements in terms of their importance in making a decision about what to do in the dilemma $(1$ = great importance, $2=$ much importance, $3=$ some importance, $4=$ little importance, $5=$ no importance).

1. Whether a community's laws are going to be upheld.

2. Isn't it only natural for a loving husband to care so much for his wife that he'd steal? 
3. Is Heinz willing to risk getting shot as a burglar or going to jail for the chance that stealing the drug might help?

4. Whether Heinz is a professional wrestler, or had considerable influence with professional wrestlers.

5. Whether Heinz is stealing for himself or doing this solely to help someone else.

6. Whether the druggist's rights to his invention have to be respected.

7. Whether the essence of living is more encompassing than the termination of dying, socially and individually.

8. What values are going to be the basis for governing how people act towards each other.

9. Whether the druggist is going to be allowed to hide behind a worthless law which only protects the rich anyhow.

10. Whether the law in the case is getting in the way of the most basic claim of any member of society.

11. Whether the druggist deserves to be robbed for being so greedy and cruel.

12. Would stealing in such a case bring about more total good for the whole society or not.

Now please rank the top four most important statements. Put the number of the statement in the blank:

Most important item

Second most important item

Third most important item

Fourth most important item

Self-monitoring scale

1. I find it difficult to imitate the behavior of other people.

2. At parties and social gatherings, I do not attempt to do or say things that others will like.

3. I can only argue for ideas which I already believe.

4. I can make important speeches even on topics about which I have almost no information.

5. I guess I put on a show to impress or entertain people.
6. I would probably make a good actor.

7. In groups of people, I am rarely the center of attention (reverse).

8. In different situations and with different people, I often act like very different persons.

9. I am not particularly good at making other people like me (reverse).

10. I am not always the person I appear to be.

11. I would not change my opinions (or the way I do things) in order to please someone else or win their favor.

12. I have considered being an entertainer.

13. I have never been good at games like charades or improvisational acting (reverse).

14. I have trouble changing my behavior to suit different people and different situations.

15. At a party, I let others keep the jokes and stories going (reverse).

16. I feel a bit awkward in company and do not show up quite as well as I should.

17. I can look anyone in the eye and tell a lie with straight face (if for a right end).

18. I may deceive people by being friendly when I really dislike them.

Consumer ethics scale

Actively benefiting from illegal activity

1. Changing price-tags on merchandise in a store.

2. Giving misleading price information to a clerk for unpriced item.

3. Drinking a can of soda in a supermarket without paying for it.

Passively benefiting from questionable practices

4. Lying about a child's age to get a lower price.

5. Getting too much change and not saying anything.

6. Not saying anything when the waitress miscalculates the bill in your favor.

Actively benefiting from deceptive (questionable) practices

7. Not telling the truth when negotiating the price of new automobile.

8. Breaking a bottle of salad dressing in a supermarket and doing nothing about it. 
No harm/no foul

9. Taping a movie off the television.

10. Using computer software or games you did not buy.

11. Recording an album instead of buying it.

12. Tasting grapes in a supermarket and not buying any.

13. Taking an ashtray or other "souvenir" from a hotel or restaurant.

14. Returning merchandise after trying it and not liking it.

15. Spending over an hour trying on different dresses and not purchasing any.

\section{Self-concept scale}

Subscale: Academic Self-Concept (30 items)

Capability

1/2 Capable of obtaining good grades (marks) at university.

3/4 Smart enough to cope with university work.

$5 / 6$ Proud of my ability in academic work at university.

7/8 Feeling good about my academic work at university.

9/10 Able to get the results I would like at university.

Perceptions of achievement

11/12 Feeling good about my assignment marks (grades) at university.

13/14 Proud of my achievements at university.

15/16 Satisfied with my academic work at university.

17/18 Happy with the academic work I do at university.

19/20 Achieving at a high level at university.

Confidence in academic life

21/22 Feeling as good as the other people in my classes at university.

23/24 Feeling involved in academic life at university.

25/26 Having a rapport with lecturers at university.

$27 / 28$ Feeling good in university classes.

29/30 Sure of myself at university.

Subscale: Social Self-Concept (30 items)

Same-sex peer self-concept
31/32 Having persons of my age and sex enjoy my company.

33/34 Having my same-sex friends have confidence in me.

35/36 Popular with others of the same-sex and age.

$37 / 38$ Able to get along well with others of the same sex.

39/40 An important person to my same-sex friends.

Opposite-sex peer self-concept

41/42 Having persons of my age and oppositesex enjoy my company.

43/44 Having my opposite-sex friends have confidence in me.

45/46 Popular with others of the same age and opposite-sex.

47/48 Able to get along well with others of opposite sex.

49/50 An important person to my opposite-sex friends.

Family self-concept

$51 / 52$ Treated fairly by my family.

$53 / 54$ Trusted by my family.

$55 / 56$ Loved by my family.

$57 / 58$ Knowing my family is proud of me.

59/60 Feeling wanted at home.

Subscale: Presentation of Self (30 items)

Physical self-concept

61/62 An attractive person.

$63 / 64$ Just as nice as I should be.

65/66 Of good physical body appearance.

67/68 Feeling that others like my physical appearance.

$69 / 70$ Not wanting to change anything about myself.

Personal confidence self-concept

$71 / 72$ Confident in myself.

73/74 A cheerful person.

Personal confidence self-concept

75/76 Satisfied with myself.

$77 / 78$ Having respect for myself.

79/80 A worthwhile person.

Subscale: Honest/Trustworthy Self-Concept

81/82 A trustworthy person.

83/84 An honest person.

$85 / 86$ Someone on whom my family can rely.

$87 / 88$ Someone on whom my friends can rely.

89/90 A person valued by others. 


\section{References}

Al-Khatib, J., K. Dobie and S. J. Vitell: 1995, 'Consumer Ethics in Developing Countries: An Empirical Investigation', Journal of Euro-Marketing 4(2), 87-105.

Al-Khatib, J., C. Roberston, M. Al-Habib and S. J. Vitell: 2002, Ethical Beliefs and Orientations in the Middle East: Are Arab Consumers Alike? Unpublished Working Paper.

Al-Khatib, J., S. J. Vitell and M. Y. A. Rawwas: 1997, 'Consumer Ethics: A Cross-Cultural Investigation', European Journal of Marketing 31(11/12), 750-767.

Arnold, D. F. Sr., and L. A. Ponemon: 1991, 'Internal Auditors' Perceptions of Whistle-Blowing and the Influence of Moral Reasoning: An Experiment', Auditing: A Journal of Practice \& Theory 10(2), 1-15.

Ashkanasy, N. M., C. A. Windsor and L. K. Trevino: 2006, 'Bad Apples in Bad Barrels Revisited: Cognitive Moral Development, Just World Beliefs, Rewards, and Ethical Decision-Making', Business Ethics Quarterly 16(4), 449-473.

Baack, D., C. Fogliasso, and J. Harris: 2000, 'The Personal Impact of Ethical Decisions: A Social Penetration Theory', Journal of Business Ethics 24(1), 39-49.

Becherer, R. C. and L. M. Richard: 1978, 'Self-Monitoring as a Moderating Variable', Journal of Consumer Research 5, 159-163.

Bodey, K. and D. Grace: 2006, 'Segmenting Service 'Complainers' and 'Non-Complainers' on the Basis of Consumer Characteristics', Journal of Services Marketing 20(3), 178-187.

Bommer, M., C. Gratto, F. Gravander and M. Tuttle: 1987, 'A Behavioral Model of Ethical and Unethical Decision Making', Journal of Business Ethics 6, 265280.

Bracken, B. A.: 1992, Multidimensional Self-Concept Scale (Pro-Ed, Texas).

Browne, B. A. and D. O. Kaldenberg: 1997, 'Conceptualizing Self-Monitoring: Links to Materialism and Product Involvement', Journal of Consumer Marketing 14(1), 31-44.

Chan, A., S. Wong and P. Leung: 1998, 'Ethical Beliefs of Chinese Consumers in Hong Kong', Journal of Business Ethics 17, 1163-1170.

Chang, C. J. and S. H. Yen: 2007, 'The Effects of Moral Development and Adverse Selection Conditions on Managers' Project Continuance Decisions: A Study in the Pacific-Rim Region', Journal of Business Ethics 76, 347-360.

Chen, Y., R. Shang and A. Lin: 2008, 'The Intention to Download Music Files in a P2P Environment: Consumption Value, Fashion, and Ethical Decision Per- spectives', Electronic Commerce Research and Applications 7(Winter), 411-422.

Cherry, J. and J. Fraedrich: 2000, 'An Empirical Investigation of Locus of Control and the Structure of Moral Reasoning: Examining the Ethical DecisionMaking Processes of Sales Managers', Journal of Personal Selling E Sales Management 20(3), 173-188.

Covey, M. K., S. Saladin and P. J. Killen: 1988, 'SelfMonitoring, Surveillance, and Incentive Effects on Cheating', The Journal of Social Psychology 129(5), 673-679.

De Pelsmacker, P., L. Driesen and G. Rayp: 2005, 'Do Consumers Care About Ethics? Willingness to Pay for Fair-Trade Coffee', The Journal of Consumer Affairs 39(2), 363-385.

DeBono, K. G.: 2006, 'Self-Monitoring and Consumer Psychology', Journal of Personality 74(3), 715-737.

Dodge, H. R., E. A. Edwards and S. Fullerton: 1996, 'Consumer Transgressions in the Marketplace: Consumer's Perspectives', Psychology and Marketing 18(8), 821-835.

Dubinsky, A. J., R. Nataraajan and W. Huang: 2005, 'Consumers' Moral Philosophies: Identifying the Idealist and the Relativist', Journal of Business Research 58, 1690-1701.

Duran, A. E.: 2008, 'Turkey Expands Fight Against Copyright Piracy', Turkish Daily News, 3 April. http:// www.turkishdailynews.com.tr/article.php?enewsid= 100499. Accessed on 8 August 2008.

Ekin, M. G. and S. H. Tezolmez: 1999, 'Business Ethics in Turkey: An Empirical Investigation with Special Emphasis on Gender', Journal of Business Ethics 18(1), 17-35.

Elm, D. R. and M. L. Nichols: 1993, 'An Investigation of the Moral Reasoning of Managers', Journal of Business Ethics 12, 817-833.

Erffmeyer, R. C., B. D. Keillor and D. T. LeClair: 1999, 'An Empirical Investigation of Japanese Consumer Ethics', Journal of Business Ethics 18, 35-50.

Ergeneli, A. and S. Arıkan: 2002, 'Gender Differences in Ethical Perceptions of Sales People: An Empirical Examination in Turkey', Journal of Business Ethics 40, 247-260.

Ferrell, O. C. and L. G. Gresham: 1985, 'A Contingency Framework for Understanding Ethical Decision Making in Marketing', Journal of Marketing 49(Summer), 87-96.

Ford, R. C. and W. D. Richardson: 1994, 'Ethical Decision Making: A Review of the Empirical Literature', Journal of Business Ethics 13, 205-221.

Gangestad, S. W. and M. Snyder: 2000, 'Self-Monitoring: Appraisal and Reappraisal', Psychological Bulletin 126(4), 530-555. 
Glover, S. H., A. B. Minnette, J. E. Logan and J. R. Ciesla: 1997, 'Re-Examining the Influence of Individual Values on Ethical Decision Making', Journal of Business Ethics 16, 1319-1329.

Goolsby, J. R. and S. D. Hunt: 1992, 'A Cognitive Moral Development and Marketing', Journal of Marketing 56(January), 55-68.

Goolsby, J. R. and H. D. Shelby: 1992, 'Cognitive Moral Development and Marketing', Journal of Marketing 56, 55-68.

Grubb, E. L. and H. L. Grathwohl: 1967, 'Consumer Self-Concept Symbolism and Market Behavior: A Theoretical Approach', Journal of Marketing 31(October), 22-27.

Guilford, J. P.: 1959, Personality (McGraw Hill, New York).

Gutkin, D. C. and J. Suls: 1979, 'The Relation Between the Ethics of Personal Conscience-Social Responsibility Principled Moral Reasoning, Journal of Youth and Adolescence 8(4), 433-441.

Hair, J. F. Jr., R. E. Anderson, R. L. Tatham and W. C. Black: 1998, Multivariate Data Analysis (Prentice Hall, New Jersey), pp. 314-321.

Heath, A. P. and D. Scott: 1998, 'The Self-Concept and Image Congruence Hypothesis: An Empirical Evaluation in the Motor Vehicle Market', European Journal of Marketing 32(11/12), 1110-1123.

Hofstede, G.: 1983, 'National Culture in Four Dimensions - A Research-Based Theory of Cultural Differences Among Nations', International Studies of Management $\mathcal{E}$ Organization 13(1-2), 46-74.

Hunt, S. D. and S. J. Vitell: 1986, 'A General Theory of Marketing Ethics', Journal of Macromarketing 6(Spring), 5-16.

Hunt, S. D. and S. J. Vitell: 1993, 'The General Theory of Marketing Ethics: A Retrospective and Revision', in N. C. Smith and J. A. Quelch (eds.), Ethics in Marketing (Irwin, Homewood, IL), pp. 775-784.

Hunt, S. D. and S. J. Vitell: 2006, 'The General Theory of Marketing Ethics: A Revision and Three Questions', Journal of Macromarketing 26, 143-152.

Husted, B. W.: 2000, 'The Impact of National Culture on Software Piracy', Journal of Business Ethics 26(3), 197-211.

Ishida, C.: 2006, 'How do Scores of DIT and MJT Differ? A Critical Assessment of the Use of Alternative Moral Development Scales in Studies of Business Ethics', Journal of Business Ethics 67, 63-74.

Izzo, G.: 2000, 'Compulsory Ethics Education and the Cognitive Moral Development of Salespeople: A Quasi-Experimental Assessment', Journal of Business Ethics 28, 223-241.
Kagitcibasi, C.: 2004, Yeni Insan ve Insanlar (Evrim Yayınevi, Istanbul), pp 360 .

Kavak, B.: 2001, 'The Effect of Role Differentiation on Ethical Judgements: A Comparative Investigation on Consumer Ethics and Work Ethics', Journal of Economics and Administrative Sciences, Hacettepe University 19(2), 79-97.

Kavak, B., P. Bayhan and S. Atakan: 2003, An Empirical Investigation on the Effect of Moral Development Level on Consumer Ethical Decision Making: An Evidence from Turkey. 1st International Business and Professional Ethics Congress of Turkey, pp. 440-452.

Kohlberg, L.: 1981, The Meaning and Measurement of Moral Development (Clark University Press, Worcester, MA).

Leone, C.: 2006, 'Self-Monitoring. Individual Differences in Orientations to the Social World', Journal of Personality 74(3), 633-657.

Loe, T. W., L. Ferrell and P. Mansfield: 2000, 'A Review of Empirical Studies Assessing Ethical Decision Making in Business', Journal of Business Ethics 25, 185-204.

Lund, D. B.: 2000, 'An Empirical Examination of Marketing Professionals' Ethical Behavior in Differing Situations', Journal of Business Ethics 24, 331-342.

Marsh, H. W.: 1990, 'A Multidimensional, Hierarchical Self-Concept: Theoretical and Empirical Justification', Educational Psychology Review 2, 77-172.

McGregor, S. L. T.: 2006, 'Understanding Consumers' Moral Consciousness', International Journal of Consumer Studies 30(2), 164-178.

Menguc, B.: 1998, 'Organizational Consequences, Marketing Ethics and Sales Force Supervision: Further Empirical Evidence', Journal of Business Ethics 17(4), 333-353.

Monga, M.: 2007, 'Managers' Moral Reasoning: Evidence from Large Indian Manufacturing Organization', Journal of Business Ethics 71, 179-194.

Muncy, J. A. and S. J. Vitell: 1992, 'Consumer Ethics: An Empirical Investigation of the Ethical Beliefs of the Final Consumer', Journal of Business Research 24(1), 297-312.

Nunnally, J.: 1978, Psychometric Theory (McGraw Hill, New York).

O'Fallon, M. and K. D. Butterfield: 2005, 'A Review of the Empirical Ethical Decision-Making Literature: 1996-2003', Journal of Business Ethics 59, 375-413.

Polonsky, M. J., P. Q. Brito, J. Pinto and N. Higgs-Kleyn: 2001, 'Consumer Ethics in the European Union: A Comparison of Northern and Southern Views', Journal of Business Ethics 31(May II), 117-130.

Powers, T. L. and R. A. Hopkins: 2006, 'Altruism and Consumer Purchase Behavior', Journal of International Consumer Marketing 19(1), 107-130. 
Rallapalli, K. C., S. J. Vitell, F. A. Wiebe and J. H. Barnes: 1994, 'Consumer Ethical Beliefs and Personality Traits: An Exploratory Analysis', Journal of Business Ethics 13(July), 487-495.

Rao, C. P. and A. A. Al-Wugayan: 2005, 'Gender and Cultural Differences in Consumer Ethics in a Consumer-Retailer Interaction Context', Journal of International Consumer Marketing 18(1/2), 45-71.

Ratner, R. K. and B. E. Kahn: 2002, 'The Impact of Private Versus Public Consumption on Variety-Seeking Behavior', Journal of Consumer Research 29, 246-257.

Rawwas, M. Y. A.: 1996, 'Consumer Ethics: An Empirical Investigation of the Ethical Beliefs of Austrian Consumers', Journal of Business Ethics 15(9), 1009-1019.

Rawwas, M. Y. A.: 2001, 'Culture, Personality and Morality a Typology of International Consumers' Ethical Beliefs', International Marketing Review 18(2), 188-211.

Rawwas, M. Y. A., G. Patzer and M. Klassen: 1995, 'Consumer Ethics in Cross Cultural Settings', European Journal of Marketing 29(7), 62-78.

Rawwas, M. Y. A., G. Patzer and S. J. Vitell: 1998, 'A Cross Cultural Investigation of the Ethical Values of Consumers: The Potential Effect of War and Civil Disruption', Journal of Business Ethics 7(March), 435-448.

Rawwas, M. Y. A. and A. Singhapakdi: 1998, 'Do Consumers' Ethical Beliefs Vary with Age? A Substantiation of Kohlberg's Typology in Marketing', Journal of Marketing 6, 26-37.

Rawwas, M. Y. A., D. Strutton and L. W. Johnson: 1996, 'An Exploratory Investigation of the Ethical Values of American and Australian Consumers', Journal of Direct Marketing 10(Autumn), 52-63.

Rawwas, M. Y. A., Z. Swaidan and J. Al-Khatib: 2006, 'Does Religion Matter? A Comparison Study of the Ethical Beliefs of Marketing Students of Religious and Secular Universities in Japan', Journal of Business Ethics 65(1), 69-86.

Rawwas, M. Y. A., Z. Swaidan and M. Oyman: 2005, 'Consumer Ethics: A Cross-Cultural Study of the Ethical Beliefs of Turkish and American Consumers', Journal of Business Ethics 57, 183-195.

Rawwas, M. Y. A., S. J. Vitell and J. A. Al-Khatib: 1994, 'Consumer Ethics: The Possible Effects of Terrorism and War on the Ethical Values of Consumers', Journal of Business Ethics 13, 223-231.

Rest, J. R.: 1979, Development in Judging Moral Issues (University of Minnesota Press, Minneapolis).

Robbin, D.: 1989, 'An Empirical Study of Moral Reasoning Among Managers', Journal of Business Ethics 8, 855-862.
Ross, W. T. and D. C. Robertson: 2003, 'A Typology of Situational Factors: Impact on Salesperson DecisionMaking About Ethical Issues', Journal of Business Ethics 46, 213-234.

Shafer, W. E., K. Fukukawa and G. M. Lee: 2007, 'Values and the Perceived Importance of Ethics and Social Responsibility: The USA Versus China', Journal of Business Ethics 70(3), 256-284.

Shavelson, R. J., J. J. Hubner and G. C. Stanton: 1976, 'Self-Concept: Validation of Construct Interpretations', Review of Educational Research 46, 407-441.

Sheppard, J. P. and M. Young: 2007, 'The Routes of Moral Development and the Impact of Exposure to the Milgram Obedience Study', Journal of Business Ethics 75, 315-333.

Singhapakdi, A., M. Rawwas, J. Marta and M. I. Ahmed: 1999, 'A Cross-Cultural Study of Consumer Perceptions About Marketing Ethics', Journal of Consumer Marketing 16(3), 257-272.

Sirgy, M. J.: 1982, 'Self-Concept in Consumer Behavior: A Critical Review', Journal of Consumer Research 9(December), 287-300.

Snyder, M.: 1974, 'Self-Monitoring of Expressive Behavior', Journal of Personality and Social Psychology 30(4), 526-537.

Snyder, M. and K. G. DeBono: 1987, 'Understanding the Functions of Attitudes: Lessons from Personality and Social Behavior', in A. R. Pratkanis, S. J. Breckler and A. G. Greenwald (eds.), Attitude Structure and Function (Erlbaum, Hillsdale NJ), pp. 339-359.

Snyder, M. and S. Gangestad: 1986, 'On the Nature of SelfMonitoring: Matters of Assessment, Matters of Validity', Journal of Personality and Social Psychology 51, 125-139.

Steenhaut, S. and P. Kenhove: 2006, 'An Empirical Investigation of the Relationships Among a Consumer's Personal Values, Ethical Ideology and Ethical Beliefs', Journal of Business Ethics 64, 137-155.

Swaidan, Z., M. Y. A. Rawwas and J. A. Al-Khatib: 2004, 'Consumer Ethics: Moral Ideologies and Ethical Beliefs of a Micro-Culture in the US', International Business Review 13, 749-761.

Tabachnick, B. G. and L. S. Fidell: 1996, Using Multivariate Statistics, 3rd Edition (HarperCollins College, New York).

Tan, B.: 2002, 'Understanding Consumer Ethical Decision Making with Respect to Purchase of Pirated Software', Journal of Consumer Marketing 19(2), 96-111.

Taylor, P. W.: 1975, Principles of Ethics: An Introduction (Dickensen, Encino, CA).

Trevino, L. K.: 1986, 'Ethical Decision Making in Organizations: A Person-Situation Interactionist Model', Academy of Management Review 11(3), 601-617. 
Trevino, L. K. and S. A. Youngblood: 1990, 'Bad Apples in Bad Barrels: A Causal Analysis of Ethical DecisionMaking Behavior', Journal of Applied Psychology 4, 378383.

Uddin, N. and P. R. Gillett: 2002, 'The Effects of Moral Reasoning and Self-Monitoring on CFO Intentions to Report Fraudulently on Financial Statements', Journal of Business Ethics 40, 15-32.

Van Kenhove, P., I. Vermeir and S. Verniers: 2001, 'An Empirical Investigation of the Relationships Between Ethical Beliefs, Ethical Ideology, Political Preference and Need for Closure', Journal of Business Ethics 32(August II), 347-361.

Vitell, S. J.: 2003, 'Consumer Ethics Research: Review, Synthesis and Suggestions for the Future', Journal of Business Ethics 43, 33-47.

Vitell, S. J., J. R. Lumpkin and M. Y A. Rawwas: 1991, 'Consumer Ethics: An Investigation of the Ethical Beliefs of Elderly Consumers', Journal of Business Ethics 10(May), 365-375.

Vitell, S. J. and J. Muncy: 1992, 'Consumer Ethics: An Empirical Investigation of Factors Influencing Ethical Judgments of the Final Consumer', Journal of Business Ethics 11(August), 585-597.

Waugh, R. F.: 2001, 'Measuring Ideal and Real SelfConcept on the Same Scale, Based on a Multifaceted, Hierarchical Model of Self-Concept', Educational and Psychological Measurement 61(1), 85-101.

Weeks, W. A., T. W. Loe, L. B. Chonko, C. R. Martinez and K. Wakefield: 2006, 'Cognitive Moral Development and the Impact of Perceived Organizational Ethical Climate on the Search for Sales Force Excellence: A Cross-Cultural Study', Journal of Personal Selling \& Sales Management 26(2), 205-217.
Wincent, J. and M. Westerberg: 2005, 'Personal Traits of CEOs, Inter-Firm Networking and Entrepreneurship in Their Firms: Investigating Strategic SME Network Participants', Journal of Developmental Entrepreneurship 10(3), 271-284.

Yaman, R. H. and E. Gurel: 2006, 'The Ethical Ideologies of Tourism Marketers', Annals of Tourism Research 33, 470-489.

Zinkhan, G. M. and J. W. Hong: 1991, 'Self-Concept and Advertising Effectiveness: A Conceptual Model of Congruency, Conspicuousness, and Response Mode', Advances in Consumer Research 18, 348-354.

Bahtışen Kavak, Canan Eryiğit and Öznur Özkan Tektaş

Department of Business Administration, Hacettepe University, Beytepe, Ankara, Turkey E-mail:bahtisenkavak@gmail.com Canan Eryiğit E-mail:canand@hacettepe.edu.tr Öznur Özkan Tektaş E-mail: oznuro@hacettepe.edu.tr

Eda Gürel

Tourism and Hotel Management Department, School of Applied Technology and Management, Bilkent University, Bilkent, Ankara, Turkey E-mail: eda@tourism.bilkent.edu.tr 